\title{
Hindering and buffering factors for parental sleep in neonatal care. A phenomenographic study
}

Ulla Edéll-Gustafsson, Charlotte Angelhoff, Ewa Johnsson, Jenny Karlsson and Evalotte Mörelius

\section{Linköping University Post Print}

\section{Tweet}

N.B.: When citing this work, cite the original article.

Original Publication:

Ulla Edéll-Gustafsson, Charlotte Angelhoff, Ewa Johnsson, Jenny Karlsson and Evalotte Mörelius, Hindering and buffering factors for parental sleep in neonatal care. A phenomenographic study, 2015, Journal of Clinical Nursing, (24), 5-6, 717-727.

http://dx.doi.org/10.1111/jocn.12654

Copyright: Wiley: 12 months http://eu.wiley.com/WileyCDA/

Postprint available at: Linköping University Electronic Press http://urn.kb.se/resolve?urn=urn:nbn:se:liu:diva-115549 


\title{
STRUCTURED ABSTRACT
}

\begin{abstract}
Aim
To explore and describe how parents of preterm and/or sick infants in neonatal care perceive their sleep.

\section{Background}

Parents experience many stressful situations when their newborn infant is preterm and/or sick. This affects bonding. By developing more family-centred care units with single-family rooms, parents are given the opportunity to stay and care for their newborn infant(s) twenty-four hours a day. Lack of sleep may affect new parents' ability to handle the situation.
\end{abstract}

\section{Design}

A phenomenographic study with an inductive and exploratory design.

\section{Methods}

Semi-structured interviews were conducted with twelve parents of infants in neonatal care between January and March 2012. To describe variations in perception of the phenomenon, data was analysed using phenomenography.

\section{Findings}

Four descriptive categories were identified within the phenomenon sleep in parents of preterm and/or sick infants in neonatal care; Impact of stress on sleep, How the environment affects sleep, Keeping the family together improves sleep, and How parents manage and prevent tiredness.

\section{Conclusion}


Anxiety, uncertainty and powerlessness have a negative influence on sleep. This can be decreased by continuous information, guidance, and practical support. Skin-to-skin-care is an important source for recovery, relaxation and sleep, and should be encouraged by the NICU nurse. The parents also mentioned the importance of being together. Having a private place where they could relax and take care of themselves and their newborn infant improved sleep. It was also desirable to involve older siblings in order to decrease feelings of loneliness, sadness and isolation.

\section{Relevance for clinical practice}

Improved parental sleep in neonatal care may help the families cope with the situation and facilitate problem-solving, emotional regulation, and the transition to parenthood. 


\section{SUMMARY BOX}

What does this paper contribute to the wider global clinical community?

- Anxiety, uncertainty and powerlessness have a negative influence on sleep, but could be decreased by continuous information, guidance, and practical support

- Keeping the family together in the neonatal care unit decreases stress and feelings of isolation, and improves sleep

- Skin-to-skin-care is an important source for recovery, relaxation and sleep for parents in neonatal care.

\section{Keywords:}

family-centred care; intensive care, neonatal; family nursing; kangaroo-mother care method; siblings; nursing; skin-to-skin-care 


\section{INTRODUCTION}

Parents of preterm infants perceive high stress at the time of the infant's admission, associated with parental role alteration and infant behaviour/appearance (Turan et al. 2008, Matricardi et al. 2013, Lasiuk et al. 2013). In family-centred care, parents are given the opportunity to stay at the unit twenty-four hours a day to care for their newborn infant (Ortenstrand et al. 2010, Morelius et al. 2012b). The stressful environment in neonatal intensive care units (NICU) affects parents negatively (Bouet et al. 2012, Schappin et al. 2013), and symptoms of posttraumatic stress may occur (Lefkowitz et al. 2010, Shaw et al. 2012). Anxiety and depression are common emotions which affect not only physical and psychological health, but may also have an adverse impact on family harmony (Kong et al. 2013). High daily stress affects sleep negatively (Morin et al. 2003, Akerstedt et al. 2012). Sleep disturbances affect functions needed for problem-solving, emotional regulation, and for the transition to parenthood (Medina et al. 2009). Data from a recent study shows that parents in NICU experience a combination of anxiety, depression, fatigue, and sleep disruption (Busse et al. 2013). However, the effect of family-centred care on parents' sleep has not been previously described.

\section{BACKGROUND}

Becoming a parent is a stressful event in life. Mothers of newborn, preterm infants experience more stress than mothers of healthy infants. It is well established that separation after birth increases stress (Nystrom \& Ohrling 2004, Lindberg \& Ohrling 2008). In accordance with the United Nations Convention of the Rights of the Child, no child should be separated from their parents. In recent years, more neonatal care units (NCU) have developed family-centred care, such as units with single-family rooms, where it is possible to care for the whole family at the same ward after birth (Ortenstrand et al. 2010, Morelius et al. 2012b). Parents' participation 
decreases stress, improves parenting confidence (Griffin \& Abraham 2006, Cooper et al. 2007), improves bonding (Crenshaw 2007), and eases the transition from hospital to the home, as the parents' competence and confidence in infant caregiving increases when caring for their infant since birth (Griffin \& Abraham 2006, Cooper et al. 2007). On the other hand, the unexpected situation, stress, anxiety, an unusual sleep environment, and frequent interruptions affect sleep negatively (Stremler et al. 2011). Sleep is necessary for normal function and recovery of all body systems. It affects physical, cognitive and mental health, the immune system and social function (Morin \& Espie 2004). The deep sleep during the first part of the night is the most important for recovery. If there are several arousals during the night, deep sleep will not occur, which leads to sleepiness, bad recovery (Markov \& Goldman 2006), and increased risk of depression (Bonnet \& Arand 2003).

Becoming a parent is associated with sleepless nights (Medina et al. 2009), regardless whether the baby is sick or healthy. Parents of healthy newborns have described a sense of persistent tiredness characterised by a range of physical, cognitive and emotional symptoms, as well as negative parental behaviours, such as high stress, low self-efficacy and greater irritability in parent-infant interactions (Cooklin et al. 2012, Giallo et al. 2013). Maternal stress contributes to sleep disturbance and depressive mood (Lee \& Hsu 2012).

Having an infant admitted to hospital decreases the ability to sleep. Parents staying with their child in hospital have reported a mean sleep duration of 4.6 hours, which is similar to the amount of sleep classified as sleep deprivation (McCann 2008). Sleep is important for parents in neonatal care as it affects their psychological and emotional health, the ability to handle the situation and take part in decisions concerning the infant. However, no study has described how parents of infants in neonatal care experience sleep when they stay with their newborn infant in NICU/NCU. 
The aim of this study was to explore and describe how parents of preterm and/or sick infants in neonatal care perceive their sleep.

\section{METHODS}

\section{Design}

A phenomenographic study with an inductive and exploratory design. Phenomenography is the empirical study of the qualitatively different ways various phenomena and aspects of the surrounding world are experienced, conceptualised, understood, perceived, and apprehended (Marton 1981). Research distinguishes between first-order and second-order perspectives, i.e. what something is and how something is perceived to be (Marton \& Booth 1997). In this study we explored the phenomenon sleep in parents of preterm and/or sick infants in neonatal care. We focused on the second-order perspective; to describe the parents' different worlds and the variations between the perspectives.

\section{Participants}

Swedish-speaking parents of different ages, with preterm and/or sick infants, who stayed at least 24 hours with their infants in NCU or NICU were included. Eight mothers and four fathers participated in the study; three mothers and three fathers were parents of twins, five mothers and one father were parents of singles. Descriptive data of the participants are presented in Table 1. The parents were recruited from one university hospital and two general hospitals in south-eastern Sweden. The infants were to be of different gestational and postnatal ages in order to receive a variation of the phenomenon. The smallest, sickest and most fragile infants, who needed constant monitoring and/or ventilation support, were cared for in open-bay rooms in the NICU. Those parents slept in a parent-room close to the ward and had free access to the NICU where they could take part in the infants' care twenty-four hours a day. Infants not in need of constant monitoring or ventilation support were cared for 
by the parents, with support from the staff, in single-bay family-rooms, where the parents slept in the same room as the infant(s). No parent included in the study slept at home. Exclusion criteria were parents of infants born with major congenital malformations, regular use of medication interfering with sleep, and parents participating in another ongoing study.

\section{Data collection}

Twelve qualitative, semi-structured interviews (EJ and JK) took place in undisturbed rooms at the ward between January-March 2012. The interview guide was designed to comprise general questions about the parent and the infant, and specific questions about sleep with follow-up questions to the parents' responses (Table 2). Two of the interviews were conducted to pilot-test the interview guide. No changes were made. There was an informal conversation for about ten minutes before the start of the recorded interview. The interviews lasted 20-45 minutes. In cases where both parents attended, the interviews were conducted separately from each other.

\section{Data analysis}

To describe variations in perception of the phenomenon, data was first analysed by three of the authors (EJ, JK, UEG), according to Dahlgren and Fallsberg's (1991) seven steps (Table 3). A review of the data, following the same steps, was made by three members of the research group (CA, UEG, EM). To enhance trustworthiness, the study has been described thoroughly throughout the research process. There is a clear presentation of the interview guide and an accurate description of the analysis and the conclusions, making the study easy to repeat. The quotations were translated by a native English speaker.

\section{Ethical considerations}


The study was approved by the Regional Committee for Medical Research (DNR 2011/1631). After receiving oral and written information about the study and an informed consent form, the parents were contacted by one of the authors (EJ or JK) to arrange a time and place for the interview. All the parents were guaranteed confidentiality and were informed that they could withdraw from the study at any time without explanation or consequences to their infant's future care.

\section{FINDINGS}

The outcome space consists of four descriptive categories within the phenomenon sleep in parents of preterm and/or sick infants in neonatal care; Impact of stress on sleep, How the environment affects sleep, Keeping the family together improves sleep, and How parents manage and prevent tiredness. The descriptive categories are presented below. The parents' perceptions are illustrated with quotations.

\section{Impact of stress on sleep}

Stress caused by anxiety, uncertainty and powerlessness, and/or inability to affect the situation, had a negative influence on sleep. Concern and uncertainty about the infant's health and the future were hard to handle. Being unable to affect the situation left a feeling of powerlessness. For some of the parents, waiting for results after examinations was difficult and feelings oscillated between hope and despair. There was always something to worry about, and not knowing what to focus on was perceived as stressful.

I'm one of those super planners, I want to be in total control of everything and now I don't have control of anything (P12)

One father experienced his daughter's apnoea as worrying and frightening. When the mother practised skin-to-skin-care with the baby in the NICU, he sat next to them, supervising the 
oxygen-saturation and heart rate at the monitor, noting every apnoea. This exhausted him, but he could not find peace to rest. For him, good days were the days when his daughter did not have any, or few apnoeas. Another father, who stayed in a parent-room while his infant was treated at the NICU, did not want to fall into deep sleep during the night. He slept with the TV and light on. He wanted to be able to be with his infant as quickly as possible in case something happened.

The staff provided important support. The parents expressed trust in the staff's caring skills. Medical knowledge and emotional support were highly valued. The parents wanted continuous information about the infant's development and condition. It was important to know not only what happened, but also why. Practical support, such as relief by staff at night, made it possible for the parents to sleep during the night, or for a few hours. This was appreciated by all the parents, but it also caused mixed feelings among some of the mothers. Although they really needed to sleep, they felt that being separated from the infant was difficult to handle.

This night was the first time we had them all night. Usually, we skip a meal and they tube feed them, that is the staff here in the NICU... you could sleep longer then (P4)

...he has actually slept two nights in another room...it was actually really hard. Because the first night it felt as if...you didn't have a child (P7)

\section{How the environment affects sleep}

Having a room to oneself where it was possible to close the door and have some privacy was considered positive among all the parents. They expressed satisfaction about having their own room where they could have their private belongings, be by themselves and manage their own time. 
We like it here. I mean, we have a room where we can sleep together and manage ourselves...it feels like we have our own space. We have somewhere to go (P11)

Those who had their infant in the NICU expressed that they felt privileged to be able to sleep in the hospital near the ward. Being able to go to the infant at any time created a feeling of security.

Even if privacy was valuable, most parents had a feeling of being "locked up" in the rooms.

You generally miss a normal life. Sitting in a room is not much fun... you feel confined and it's hard (P3)

Mothers who were breastfeeding felt particularly isolated. Some parents mentioned how they could not use their mobile phone at the ward to contact friends and others outside the hospital, as mobile phones were not allowed at the wards. One hospital offered free wireless Internet access. This was appreciated as it gave the parents a chance to connect with the world outside the hospital without leaving the room. Some parents missed a common room for siblings to play, and where they could meet other parents in the same situation.

Parents with infants in the NICU felt that the environment with a lot of equipment was very unfamiliar and stressful. The beeping from monitors in the open-bay room affected them. Parents sleeping in the same room as infants monitored with oxygen-saturation and heart ratealarm were affected by beeping sounds during the night. Alarms and impaired values fuelled worry and fear, while false alarms were stressful and annoying.

the main disturbances have been the machines, I mean the sounds they've made when we've had them in the room $(\mathrm{P} 2)$

Some parents were bothered by noise outside the rooms during the night, while others thought the rooms were well isolated or did not care about the noise.

I think it's really nice and quiet. You do hear some beeping and people walking, but I like that. I don't like when it's completely quiet. So that doesn't bother me (P8) 
All parents had opinions about the beds, and they were described both as being too soft and too hard. They appreciated having a bed close to their partner's bed. Their thoughts about temperature pended between it being too warm, too hot or irregular. One mother reacted to the hospital smell and the dry air, giving her trouble breathing when she was sleeping. All parents wanted it to be dark when they were sleeping and wished for better blinds. Some parents wanted some form of nightlight or a light with a dimmer switch, so that they did not have to switch on the light when they were checking on their infant during the night.

For a change of scenery, the parents could take a walk outdoors in order to get some daylight and fresh air. They went to the supermarket or checked on their own house. This gave them valuable time to discuss and exchange thoughts with their partner, and helped them to reflect upon and handle the situation.

...it has been quite nice. To get away...It will be nice to get away and think about other things. Get some fresh air above all (P5)

Overall, the parents said that they did not have any high expectations on the hospital environment. They expressed satisfaction and had adapted well to sleeping in the hospital, even if it was hard the first few nights.

\section{Keeping the family together improves sleep}

The parents described how they suddenly and unexpectedly became parents, and that this was hard to understand in the beginning. They started to get to know their infant following the delivery. It was easier to bond if they could establish eye contact and see their infant's facial expression. The parents felt responsible for their infants and tried to be with them as much as possible. Taking over the infant's daily care in a family-room was a big step in the transition to parenthood and gave the parents a feeling of independence. Some mothers were cared for at another ward after having had a caesarian section, and their partners expressed that they felt 
torn as they wanted to be both with the mother and the infant. They felt safe when they could all sleep in the same room.

It feels safer now that I have him [the baby] in the room. I hear his breathing and that calms me down because I can hear that he's calm, so that actually feels safer (P6)

Some mothers slept by themselves in the NCU, while their partners were at home with older siblings. The families were divided, and the mothers expressed feelings of loneliness, sadness and isolation, especially during the evenings and nights, and wanted the family to be together. One mother expressed that she slept much better when her husband was there. Those who had older children at home longed for them and expressed a desire to spend more time with the family.

We're going to try to bring them here one at a time so that they can stay a bit longer. It is a bit cumbersome bringing them all at the same time, there's quite a few of them. It gets quite lively when there are that many children *laughter* it can become a bit much with the tiny babies that are here, so I suppose you have to take a bit at a time $(\mathrm{P} 10)$

One mother felt insecure about the sad goodbyes, and did not know if she thought it was good for the sibling to visit her and the infant or not. Another mother said that when their infant was in the NICU, the rest of the family chose to live all together in a parent-room near the ward. They found activities around the hospital instead of home, and did not have to split up the family.

\section{How parents manage and prevent tiredness}

The parents fell asleep without problems in the evening. They expressed a physical tiredness and were longing to go to bed for the night. They planned and prepared their tasks before the night, to optimise their sleeping time. The time aspect was important; when they went to bed, and how many hours of sleep they had before waking up. They described how they woke up 
several times during the night. Those who had their infant in the same room were affected by the infant's needs, personality and circadian rhythm. They experienced that it was hard to get up in the night and feed the infant because of tiredness.

...then I usually sleep, try to sleep or rest at least until it's time again. Then we breastfeed and tube feed, I express milk and then I go to bed again so I can sleep for about one and a half hour and then it's time again at half past one and then I sleep and then it's time at half past four and then I sleep again. (P4)

Some parents described that it was harder to get up at the beginning of the night, while others thought it was worse early in the morning.

It feels great really, because I have a son... at first when I wake up I can feel tired, but at the same time I hear him and then I feel really happy (P6)

I feel really rested in the morning, but it creeps up on me in the afternoon and that's when I feel tired and irritable. That's when I most often feel sad too, but that's because I'm tired (P11)

Tiredness was expected among the parents. They described a psychological tiredness, with cognitive symptoms such as forgetfulness and changed behaviour, which led to annoyance and depressive feelings. The parents also described a physical tiredness, with dizziness and worse ability to perform activities. Most of the parents described a distinct tiredness.

Some of the parents rested during the day and one father slept for a short while every day. Activity at the ward and worries about the infant and the future were barriers for relaxation. I find it difficult to relax in here. You never know if someone's coming in (P3)

Another perception was that there was no time for relaxation as the infant needed to eat regularly, and the mother was supposed to express milk and feed herself.

Practising skin-to-skin-care and being close to the infant were stress-reducing factors that gave a feeling of control, which was appreciated by all the parents. Those moments were 
experienced as relaxing, cosy and joyful. Being close to their infants was important for all parents. One mother expressed a feeling of freedom when she could walk around the ward, skin-to-skin, with her infant in a baby sling.

It feels good. The first minutes are always, I'm always a bit nervous before and... it's, well it's a bit scary. But when you do sit with her, it feels great, two hours simply disappear...it feels as if you've only sat there for a short while (P9)

When you hold them in your arms you sometimes fall asleep, it's very nice and peaceful...a lovely part of the day (P12)

Some parents mentioned that they wanted more physical activity, especially fathers who did not have any physical barriers in relation to giving birth. They thought they would feel and sleep better if they were more physically active. At the same time, they did not want to leave their infants for too long and wished for activities in the hospital area.

\section{DISCUSSION}

Parents in the NICU go through an emotional roller-coaster with feelings of anxiety, uncertainty and powerlessness due to their infant's health, which has been described in earlier studies (Watson 2011, Arnold et al. 2013). The parents in our study described how they lacked a feeling of control, and that this affected them negatively. The NICU experience, waiting for examination results, and not knowing what would happen next were mentioned as very stressful. Fathers in particular expressed worries about their infant and the situation, and the effects on their well-being and sleep. Turan et al. (2008) report a high mean stress score in fathers, which they assume could be explained by fathers taking more responsibility in the beginning of the infant's admission to the NICU because of the mother's health status. Shaw et al. (2009) show that four months after the infant's preterm birth, 33\% of the fathers and 9\% of the mothers meet the criteria for posttraumatic stress disorder. 
One could wonder if too much is expected from parents when we expect them to practice family-centred care 24 hours per day. To our knowledge, there are no studies reporting negative effects of family-centred care. A recent study, on the other hand, shows that the parents desire to participate in their hospitalized children's care more than they actually do (Romaniuk et al. 2014). Family-centred care is supported by earlier studies where parents reported how they wanted to take responsibility of the child's care (Wigert et al. 2010), and how taking care of their infant empowered them and helped them to find their parental role, which made it easier to cope with the situation (Heinemann et al. 2013).

It is not just stress that affects a person's overall well-being, but how the individual copes with stress as well. If coping is effective, stress will remain under control (Lazarus et al. 1974). Coping relates to our efforts to manage adaption and the feelings that are generated (Lazarus 2006). A feeling of control was considered important to the parents in our study, and they found ways to cope. One example is the father who counted his daughter's apnoeas. Blomqvist et al. (2012b) describe that taking an active part in the infant's care and spending time together enhance the feeling of becoming a father, which makes the fathers feel that they have control. The NICU nurse must be one step ahead and support the parents by providing continuous information about the situation and expectations, and guide the parents in their new role in order to prevent posttraumatic stress syndrome and depression.

In the present study, privacy and integrity were highly valued. These were facilitated by having a room to oneself. Being together in a private room, taking care of themselves and their newborn infant improved the parents' sleep and decreased the feeling of stress. However, there was a persistent feeling of isolation that seemed to be connected with the situation rather than the environment. The parents missed their social life with friends and relatives. Family-centred care focuses on the two-generation family and not the extended family. An earlier study describes how grandmothers want to support the parents, but do not 
know how they can help (Frisman et al. 2012). On the other hand, that study includes grandparents living close to the family. Not all families have their relatives living nearby.

Due to local regulations at the hospitals, using mobile phones in the wards was not permitted. One hospital had free Internet access. Today, mobile phones are not only used for phone calls, but they are also used for short messages, they include a camera and provide Internet access etc. According to Bessiére et al. (2010), using the Internet to communicate with family and friends is beneficial for well-being and decreases the risk for depression. Cotten et al. (2013) found that Internet use among older adults at risk of social isolation is associated with lower levels of loneliness. Using the Internet in the NCU is a topic for discussion, as parents should be focusing on the infant's signals to improve attachment. However, social well-being is important for parents as well, and the Internet is an everyday communication tool for most people today.

Thanks to Swedish parental leave policies, both parents have a rather unique opportunity to stay at the hospital with their preterm infant(s). However, one parent often needs to stay at home with older siblings. Generous guidelines for visiting are preferred to decrease the stressful situation that results from the feeling of being torn between the infant and the older siblings (Blomqvist et al. 2012a). One reason for visiting restrictions for siblings could be the application of the Newborn Individualized Care and Assessment Program among Swedish units, which emphasises a quiet environment to support the infant's capabilities for selfregulation and interaction with the parents (Greisen et al. 2009). Another reason could be the risk of infections (Frisman et al. 2012). The hospitals included in the present study welcomed siblings to visit, and they were given the opportunity to stay overnight. One family in our study appreciated this and stayed all together, despite the inconvenience of not being at home. Lack of playrooms at the wards limited visits by siblings. No matter the age, siblings are members of the family, and a room for playing and socialising are desirable. Uncertainty 
about allowing siblings to visit the NICU or not could be decreased through information on how NICU visits may affect children, and help explaining the medical condition to the children (Latva et al. 2007). The whole family should be involved in family-centred care to decrease feelings of loneliness, sadness and isolation.

Tiredness was expected and understandable among the parents. Becoming a parent is associated with sleepless nights. They talked about practical and psychological difficulties regarding finding some rest during the day due to the infant's needs, expressing milk, getting food for themselves, the constant activity at the ward, and worries about the future. All parents mentioned skin-to-skin-care as a stress-reducing factor and described the positive feelings they experienced when they held their infant close. It has been reported that caring for the infant, breastfeeding and skin-to-skin-care is meaningful to parents with infants in the NICU, as these factors improve the transition to parenthood, give them a sense of influence, and moderate their sense of helplessness (Skene et al. 2012, Lasiuk et al. 2013). Skin-to-skincare is frequently used in Sweden (Morelius et al. 2012a). It triggers and strengthens the bond between parents and their infant (Arnold et al. 2013), and helps the parents to develop their parental role and cope with unexpected situations (Blomqvist et al. 2012b). In the present study, parents expressed nervousness in the beginning of skin-to-skin-care, but this faded away over time, and became a very important part of the day. It has been shown that heart rate and stress level decrease when the mother has adapted to skin-to-skin-care (Morelius $e t$ al. 2005). It is important that the NICU nurse supports and helps the parents to skin-to-skincare, in order to improve bonding and give the parents a moment of relaxation and recovery. Some parents in our study missed being able to be physically active and thought they would feel and sleep better if they had an opportunity to go for a walk outside, or a gym nearby. There is a connection between physical activity and sleep. Mothers who spend less time on daytime activity are at higher risk of postpartum depressive symptoms (Lee et al. 2012). By 
enhancing physiological conditions that promote sleep, such as depleting energy stores, breaking down tissue, and elevating body temperature, exercise has been shown to improve sleep in individuals affected by anxiety and depression (Asmundson et al. 2013). This could easily be achieved by simple activities such as a walk outdoors or using an exercise bike at the ward. It is important that the staff give the parents the time and opportunity to be physically active every day, and support and encourage them to be so.

A strength with this study was that the sample included both mothers and fathers of different ages to infants with different gestational and postnatal age. Some were parents of twins and some had older children at home, which made it possible to capture as many different perceptions and experiences of the phenomenon as possible. The study was conducted in three different hospitals. However, all hospitals were located in the same geographical region of Sweden. Neonatal care might differ depending on culture and hospital policies, which could affect the findings. Furthermore, parents in NCU/NICU are in a vulnerable and exposed situation. This might have influenced their answers even though they were informed that their participation would not affect their infant's care.

\section{CONCLUSIONS}

Keeping the family together improves sleep. Therefore, family-centred care is valuable in NCU/NICU. Having a private place where the family could be together, relax, and take care of themselves and their newborn infant improved sleep. It is also desirable to involve older siblings in family-centred care by offering them information, activities, and a place to play and socialise, in order to decrease feelings of loneliness, sadness and isolation in the family. To prevent anxiety, uncertainty and powerlessness, the health professionals should provide continuous information, guidance, and practical support to the parents. It is also important to encourage parents to skin-to-skin-care as it is an important source for recovery and relaxation, 
and give parents opportunities for physical activity to improve sleep and decrease the risk for depressive symptoms.

\section{RELEVANCE FOR CLINICAL PRACTICE}

Earlier studies have described how parents with infants in neonatal care are affected by feelings of anxiety, uncertainty and powerlessness due to their infant's health. This study highlights how the parents perceive their own sleep. To our knowledge, this is the first study focusing on this aspect. It is important that health professionals understand the importance of sleep for parents with infants in neonatal care. Improved parental sleep may help the families cope with the situation, and facilitate problem-solving, emotional regulation, and the transition to parenthood. 


\section{References}

Akerstedt, T., Orsini, N., Petersen, H., Axelsson, J., Lekander, M. \& Kecklund, G. (2012) Predicting sleep quality from stress and prior sleep--a study of day-to-day covariation across six weeks. Sleep Medicine 13(6), 674-679.

Arnold, L., Sawyer, A., Rabe, H., Abbott, J., Gyte, G., Duley, L., Ayers, S. \& 'Very Preterm Birth Qualitative Collaborative Group' (2013) Parents' first moments with their very preterm babies: a qualitative study. BMJ open 3(4), e002487.

Asmundson, G.J., Fetzner, M.G., Deboer, L.B., Powers, M.B., Otto, M.W. \& Smits, J.A. (2013) Let's get physical: a contemporary review of the anxiolytic effects of exercise for anxiety and its disorders. Depression and Anxiety 30(4), 362-373.

Bessiere, K., Pressman, S., Kiesler, S. \& Kraut, R. (2010) Effects of Internet use on health and depression: A longitudinal study. Journal of Medical Internet Research 12(1).

Blomqvist, Y.T., Frolund, L., Rubertsson, C. \& Nyqvist, K.H. (2012a) Provision of Kangaroo Mother Care: supportive factors and barriers perceived by parents. Scandinavian Journal of Caring Sciences 27, 345-353.

Blomqvist, Y.T., Rubertsson, C., Kylberg, E., Joreskog, K. \& Nyqvist, K.H. (2012b) Kangaroo Mother Care helps fathers of preterm infants gain confidence in the paternal role. Journal of Advanced Nursing 68(9), 1988-1996.

Bonnet, M.H. \& Arand, D.L. (2003) Clinical effects of sleep fragmentation versus sleep deprivation. Sleep Medicine Reviews 7(4), 297-310. 
Bouet, K.M., Claudio, N., Ramirez, V. \& Garcia-Fragoso, L. (2012) Loss of parental role as a cause of stress in the neonatal intensive care unit. Boletin de la Asociacion Medica de Puerto Rico 104(1), 8-11.

Busse, M., Stromgren, K., Thorngate, L. \& Thomas, K.A. (2013) Parents' responses to stress in the neonatal intensive care unit. Critical Care Nurse 33(4), 52-59.

Cooklin, A.R., Giallo, R. \& Rose, N. (2012) Parental fatigue and parenting practices during early childhood: an Australian community survey. Child: Care, Health and Development 38(5), 654-664.

Cooper, L.G., Gooding, J.S., Gallagher, J., Sternesky, L., Ledsky, R. \& Berns, S.D. (2007) Impact of a family-centered care initiative on NICU care, staff and families. Journal of Perinatology 27 Suppl 2, S32-7.

Cotten, S.R., Anderson, W.A. \& McCullough, B.M. (2013) Impact of internet use on loneliness and contact with others among older adults: cross-sectional analysis. Journal of Medical Internet Research 15(2), e39.

Crenshaw, J. (2007) Care practice \#6: no separation of mother and baby, with unlimited opportunities for breastfeeding. The Journal of Perinatal Education 16(3), 39-43.

Dahlgren, L.O. \& Fallsberg, M. (1991) Phenomenography as an approach to research in social pharmacy. Journal of Social and Administrative Pharmacy 8(4), 150-156.

Frisman, G.H., Eriksson, C., Pernehed, S. \& Morelius, E. (2012) The experience of becoming a grandmother to a premature infant - a balancing act, influenced by ambivalent feelings. Journal of Clinical Nursing 21(21-22), 3297-3305. 
Giallo, R., Rose, N., Cooklin, A. \& McCormack, D. (2013) In survival mode: mothers and fathers' experiences of fatigue in the early parenting period. Journal of Reproductive and Infant Psychology 31(1), 31-45.

Greisen, G., Mirante, N., Haumont, D., Pierrat, V., Pallás-Alonso, C.R., Warren, I., Smit, B.J., Westrup, B., Sizun, J., Maraschini, A. \& Cuttini, M. (2009) Parents, siblings and grandparents in the Neonatal Intensive Care Unit A survey of policies in eight European countries. Acta Paediatrica 98(11), 1744-1750.

Griffin, T. \& Abraham, M. (2006) Transition to home from the newborn intensive care unit: applying the principles of family-centered care to the discharge process. The Journal of Perinatal \& Neonatal Nursing 20(3), 243-9; quiz 250-1.

Heinemann, A.B., Hellstrom-Westas, L. \& Nyqvist, K.H. (2013) Factors affecting parents' presence with their extremely preterm infants in a neonatal intensive care room. Acta Paediatrica, 102, 695-702.

Kong, L., Cui, Y., Qiu, Y., Han, S., Yu, Z. \& Guo, X. (2013) Anxiety and depression in parents of sick neonates: A hospital-based study. Journal of Clinical Nursing 22(7-8), 1163-1172.

Lasiuk, G.C., Comeau, T. \& Newburn-Cook, C. (2013) Unexpected: an interpretive description of parental traumas' associated with preterm birth. BMC Pregnancy and Childbirth 13 Suppl 1, S13.

Latva, R., Lehtonen, L., Salmelin, R.K. \& Tamminen, T. (2007) Visits by the family to the neonatal intensive care unit. Acta Paediatrica 96(2), 215-220. 
Lazarus R S, Averill J R, Opton E M (1974) The psychology of coping: Issues of research and assessment. In Coping and Adaption (Coelho, Hamburg \& Adams ed.), Basic Books, New York, pp. 249-315.

Lazarus, R.S. (2006) Emotions and interpersonal relationships: toward a person-centered conceptualization of emotions and coping. Journal of Personality 74(1), 9-46.

Lee, S.Y., Grantham, C.H., Shelton, S. \& Meaney-Delman, D. (2012) Does activity matter: an exploratory study among mothers with preterm infants? Archives of Women's Mental Health 15(3), 185-192.

Lee, S.Y. \& Hsu, H.C. (2012) Stress and health-related well-being among mothers with a low birth weight infant: the role of sleep. Social Science \& Medicine 74(7), 958-965.

Lefkowitz, D.S., Baxt, C. \& Evans, J.R. (2010) Prevalence and correlates of posttraumatic stress and postpartum depression in parents of infants in the Neonatal Intensive Care Unit (NICU). Journal of Clinical Psychology in Medical Settings 17(3), 230-237.

Lindberg, B. \& Ohrling, K. (2008) Experiences of having a prematurely born infant from the perspective of mothers in northern Sweden. International Journal of Circumpolar Health 67(5), 461-471.

Markov, D. \& Goldman, M. (2006) Normal sleep and circadian rhythms: neurobiologic mechanisms underlying sleep and wakefulness. The Psychiatric Clinics of North America 29(4), 841-53.

Marton F (1981) Phenomenography - Describing conceptions of the world around us. Instructional Science 10, 177-200. 
Marton F \& Booth S (1997) Learning and awareness. New Jersey: Lawrence Erlbaum Associates.

Matricardi, S., Agostino, R., Fedeli, C. \& Montirosso, R. (2013) Mothers are not fathers: differences between parents in the reduction of stress levels after a parental intervention in a NICU. Acta Paediatrica 102(1), 8-14.

McCann, D. (2008) Sleep deprivation is an additional stress for parents staying in hospital. Journal for Specialists in Pediatric Nursing 13(2), 111-122.

Medina, A.M., Lederhos, C.L. \& Lillis, T.A. (2009) Sleep disruption and decline in marital satisfaction across the transition to parenthood. Families, Systems \& Health 27(2), 153160.

Morelius, E., Theodorsson, E. \& Nelson, N. (2005) Salivary cortisol and mood and pain profiles during skin-to-skin care for an unselected group of mothers and infants in neonatal intensive care. Pediatrics 116(5), 1105-1113.

Morelius, E., Angelhoff, C., Eriksson, J. \& Olhager, E. (2012a) Time of initiation of skin-toskin contact in extremely preterm infants in Sweden. Acta Paediatrica 101(1), 14-18.

Morelius, E., Brostrom, E.B., Westrup, B., Sarman, I. \& Ortenstrand, A. (2012b) The Stockholm Neonatal Family-Centered Care Study: effects on salivary cortisol in infants and their mothers. Early Human Development 88(7), 575-581.

Morin C M \& Espie C A (2004) Insomnia: A clinical guide to assessment and treatment. New York: Springer Science. 
Morin, C.M., Rodrigue, S. \& Ivers, H. (2003) Role of stress, arousal, and coping skills in primary insomnia. Psychosomatic Medicine 65(2), 259-267.

Nystrom, K. \& Ohrling, K. (2004) Parenthood experiences during the child's first year: literature review. Journal of Advanced Nursing 46(3), 319-330.

Ortenstrand, A., Westrup, B., Brostrom, E.B., Sarman, I., Akerstrom, S., Brune, T., Lindberg, L. \& Waldenstrom, U. (2010) The Stockholm Neonatal Family Centered Care Study: effects on length of stay and infant morbidity. Pediatrics 125(2), e278-85.

Romaniuk, D., O'Mara, L. \& Akhtar-Danesh, N. (2014) Are parents doing what they want to do? Congruency between parents' actual and desired participation in the care of their hospitalized child. Issues in Comprehensive Pediatric Nursing, Early Online: 1-19. DOI:10.3109/01460862.2014.880532.

Schappin, R., Wijnroks, L., Uniken Venema, M.M. \& Jongmans, M.J. (2013) Rethinking stress in parents of preterm infants: a meta-analysis. PloS one 8(2), e54992.

Shaw, R.J., Bernard, R.S., Deblois, T., Ikuta, L.M., Ginzburg, K. \& Koopman, C. (2009) The relationship between acute stress disorder and posttraumatic stress disorder in the neonatal intensive care unit. Psychosomatics 50(2), 131-137.

Shaw, R.J., Bernard, R.S., Storfer-Isser, A., Rhine, W. \& Horwitz, S.M. (2013) Parental Coping in the Neonatal Intensive Care Unit. Journal of Clinical Psychology in Medical Settings 20(2), 135-142.

Skene, C., Franck, L., Curtis, P. \& Gerrish, K. (2012) Parental involvement in neonatal comfort care. Journal of Obstetric, Gynecologic, and Neonatal Nursing 41(6), 786-797. 
Stremler, R., Dhukai, Z., Wong, L. \& Parshuram, C. (2011) Factors influencing sleep for parents of critically ill hospitalised children: a qualitative analysis. Intensive \& Critical Care Nursing 27(1), 37-45.

Turan, T., Basbakkal, Z. \& Ozbek, S. (2008) Effect of nursing interventions on stressors of parents of premature infants in neonatal intensive care unit. Journal of Clinical Nursing 17(21), 2856-2866.

Watson, G. (2011) Parental liminality: A way of understanding the early experiences of parents who have a very preterm infant. Journal of Clinical Nursing 20(9-10), 14621471.

Wigert, H., Berg, M. \& Hellstrom, A.L. (2010) Parental presence when their child is in neonatal intensive care. Scandinavian Journal of Caring Sciences 24(1), 139-146. 
Table 1: Descriptive data of the participants in the study $(n=12)$

\begin{tabular}{|c|c|c|c|c|c|c|c|}
\hline $\begin{array}{l}\text { Parent } \\
\text { (P) }\end{array}$ & $\begin{array}{l}\text { Mother } \\
(\mathrm{m}) / \\
\text { father (f) }\end{array}$ & $\begin{array}{l}\text { Age of } \\
\text { the } \\
\text { parent }\end{array}$ & $\begin{array}{l}\text { Gestational } \\
\text { age } \\
\text { of the child } \\
\text { (week) }\end{array}$ & $\begin{array}{l}\text { Postnatal } \\
\text { age } \\
\text { of the } \\
\text { child } \\
\text { (days) }\end{array}$ & $\begin{array}{c}\text { Siblings } \\
\text { at home } \\
n\end{array}$ & Twins & $\begin{array}{c}\text { Family- } \\
\text { room } \\
(\mathrm{FR}) / \\
\text { parent- } \\
\text { room } \\
(\mathrm{PR})\end{array}$ \\
\hline $\mathrm{P} 1$ & $\mathrm{~m}$ & 36 & $31+0$ & 46 & 0 & yes & FR \\
\hline $\mathrm{P} 2$ & $\mathrm{f}$ & 40 & $31+0$ & 46 & 0 & yes & FR \\
\hline P3 & $\mathrm{m}$ & 23 & $39+6$ & 8 & 1 & no & FR \\
\hline P4 & $\mathrm{m}$ & 31 & $34+4$ & 13 & 0 & yes & FR \\
\hline P5 & $\mathrm{f}$ & 34 & $34+4$ & 13 & 0 & yes & FR \\
\hline P6 & $\mathrm{m}$ & 39 & $29+?$ & 35 & 2 & no & FR \\
\hline P7 & $\mathrm{m}$ & 36 & $29+4$ & 14 & 1 & no & FR \\
\hline P8 & $\mathrm{m}$ & 30 & $36+0$ & 7 & 1 & no & FR \\
\hline P9 & $\mathrm{f}$ & 31 & $29+6$ & 11 & 4 & no & PR \\
\hline P10 & $\mathrm{m}$ & 28 & $29+6$ & 11 & 4 & no & PR \\
\hline P11 & $\mathrm{m}$ & 30 & $29+1$ & 8 & 0 & yes & PR \\
\hline P12 & $\mathrm{f}$ & 42 & $29+1$ & 8 & 0 & yes & PR \\
\hline
\end{tabular}


Table 2 Interview guide

\section{General questions:}

Male/female, parent's age, gestational and postnatal age of the child, marital status, siblings Specific questions:

- How long have you been here?

- Can you tell me little about your infant?

- Can you tell me about the last twenty-four hours? Diet, exercise, rest, feelings

- What is it like to sleep here? Sleep quality, time, arousals - how/why, light, dark, quiet, disturbing noises

- How do you feel when you are going to sleep?

- How do you feel in the morning when you wake up?

- Where do you sleep?

- Where does your infant sleep?

- What affects your sleep? Makes you sleep good/bad

- How do you perceive your sleep before your infant was born?

- Can you mention anything that could facilitate/improve your sleep?

\section{Subsequent questions:}

Tell me... how was it? Can you tell me more... Can you expand on? What do you think is the reason for that? You previously said that... can you give an example? How do you mean? 


\section{Table 3}

The seven phenomenographic analysis steps according to Dahlgren and Fallsberg (1991)

1. Familiarization: To become familiar with and obtain an overall impression of the data, the interviews were transcribed and read several times.

2. Condensation: The most significant perceptions of the phenomenon were identified. Sentences were marked and key words were listed in the margin. Long answers were condensed to obtain the central parts of the phenomenon.

3. Comparison: The significant perceptions were compared with each other to find variations and similarities. By cutting out coded, significant perceptions from the transcribed interviews, a comparison could subsequently be made.

4. Grouping: Similar perceptions were grouped into preliminary categories. The different categories were colour coded. This process was repeated several times during the analysis.

5. Articulating: The different categories were compared in an attempt to reduce them. The categories were revised several times to achieve a satisfying result.

6. Labelling: A linguistic expression was denoted for each category with the emphasis on their essence. These are the categories described in the findings of the study.

7. Contrasting: The unique characters of every category as well as the similarities with the other categories were described. 